\title{
Twenty years of the Journal of Solid State Electrochemistry
}

\author{
Fritz Scholz ${ }^{1}$
}

Received: 3 May 2017 / Accepted: 12 May 2017/Published online: 19 May 2017

(C) Springer-Verlag Berlin Heidelberg 2017

It is now 20 years since the first edition of our Journal appeared, in July 1997. This is an appropriate moment to look back on its foundation and to look forward to the future. The motivating idea all those years ago was that electrochemistry in condensed matter was emerging as the focus of several new fields of research, particularly energy technologies and nanotechnologies, and that a forum for the dissemination and exchange of new ideas was urgently needed. The Journal of Solid State Electrochemistry was the result. The continuing success of the journal has fully justified those original thoughts.

The founding members of the Editorial Board realized that "solid state electrochemistry" was poised for a rapid evolution and would soon diversify away from its historical base in solid state ionics. This soon came to pass. Thus, whenever the structure of a condensed phase was found to be responsible for novel electrochemistry, whether it is crystalline, liquid crystalline, or amorphous, the Board members agreed that it was a topic fitting for our journal. In this spirit, a new field of electrochemistry was born. The pioneering members of the Editorial Board and Regional Editors were A. J. Bard, V. Z. Barzukov, F. G. K. Baucke, J. O. Besenhard, J. O'M. Bockris, A. M. Bond, K. Z. Brainina, U. Guth, N. Hackerman, A. Hamnett, K. Itaya, P. J. Kulesza, M. Lovrić, M. Lyons, H. B. Mark Jr., H.-H. Möbius, K. B. Oldham, P. Sanchez-Batanero, R. Schoellhorn, G. V. Subba Rao, D. E. Tallman, J.-M. Tarascon, I. Uchida, V.

Fritz Scholz

fscholz@uni-greifswald.de

1 Institute of Biochemistry, University of Greifswald, Felix-Hausdorff-Str.4, 17487 Greifswald, Germany
Vigdergauz, A. K. Vijh, and N. F. Zakharchuk. I thank them all for their extraordinary efforts.

The 20th anniversary of the founding of our Journal is also an appropriate moment to mourn the passing of colleagues who have died during the intervening years: F. G. K. Baucke, J. O. Besenhard, J. O’M. Bockris, N. Hackerman, H. B. Mark Jr., and H.-H. Möbius. They all shaped the journal with their unique personalities, besides contributing scientific input at the very highest level.

Since 1999, Dr. Michael Hermes has helped me to manage the torrent of submissions, and since 2006, he served as Managing Editor. Everyone connected with the journal owes him a debt of thanks for the rigorous scrutiny and continuous enthusiasm with which he checks all the submitted manuscripts before they are distributed to editors. Without this crucial work, we could not run the journal!

The success of a scientific journal may be judged by many different criteria: the most important, in my eyes, is the quality of its authors. In particular, if world leading experts choose to submit their own work to the journal, then we have achieved our goal. I am pleased to confirm that the journal today attracts a very talented authorship. Space is limited, and competition to fill it is high. For example, more than 1000 manuscripts were submitted during the last calendar year, and only the top third were accepted for publication. Bearing in mind that we get practically no "junk manuscripts," this is a good indicator of quality. Another important criterion is the Impact Factor. From the foundation of the journal until today, this has more than doubled, from 1.1 to 2.3. This strongly indicates that the readership of the Journal is absorbing (and citing) the science provided.

The journal began life under the auspices of Peter Enders at the Springer office in Heidelberg. Later, Dr. Steffen Pauly continued this work, and now Dr. Svetlana Zakharchenko is my partner on the publisher's side. It is my sincere pleasure to thank them all. I am also grateful to many other Springer staff 


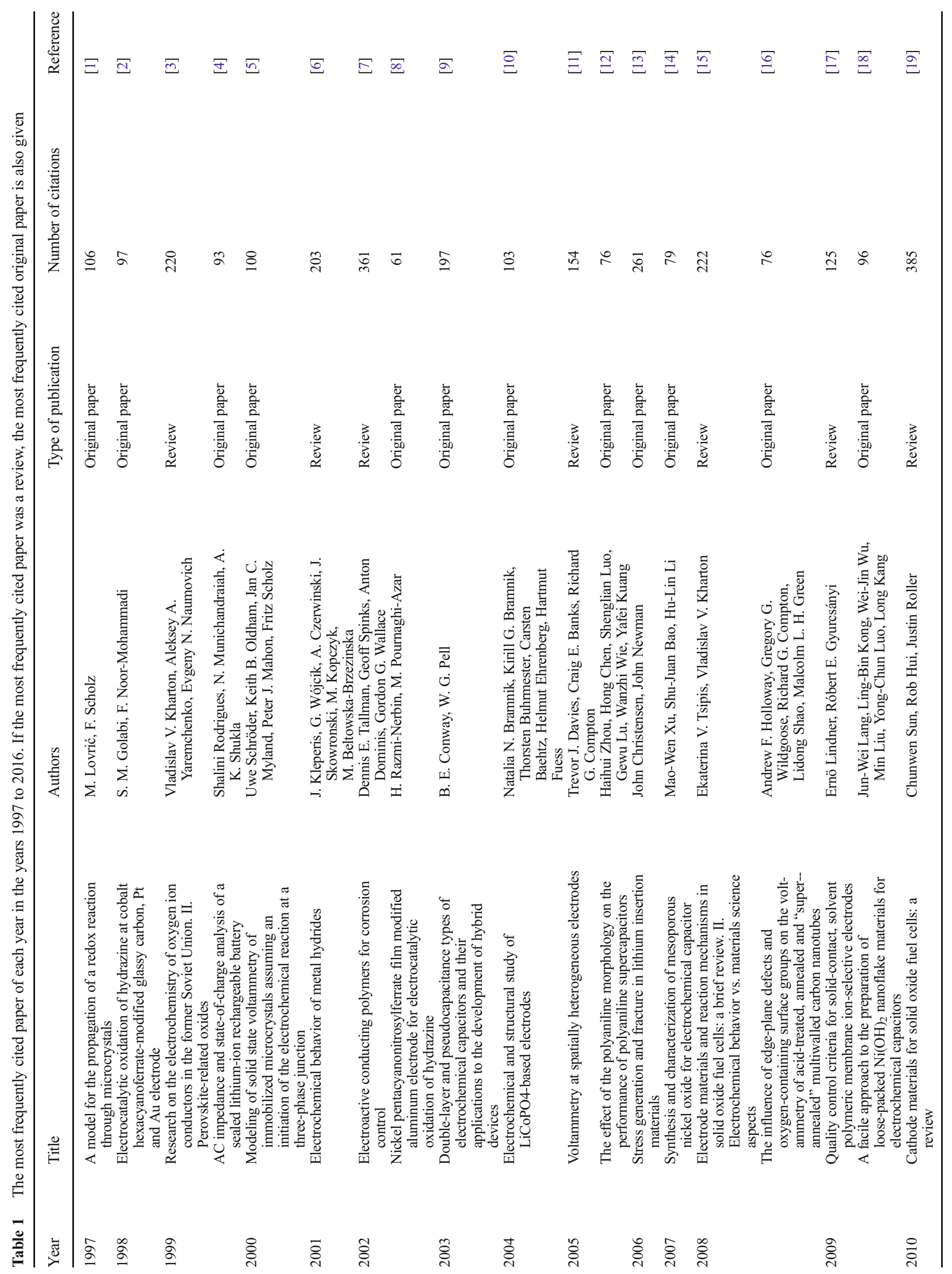




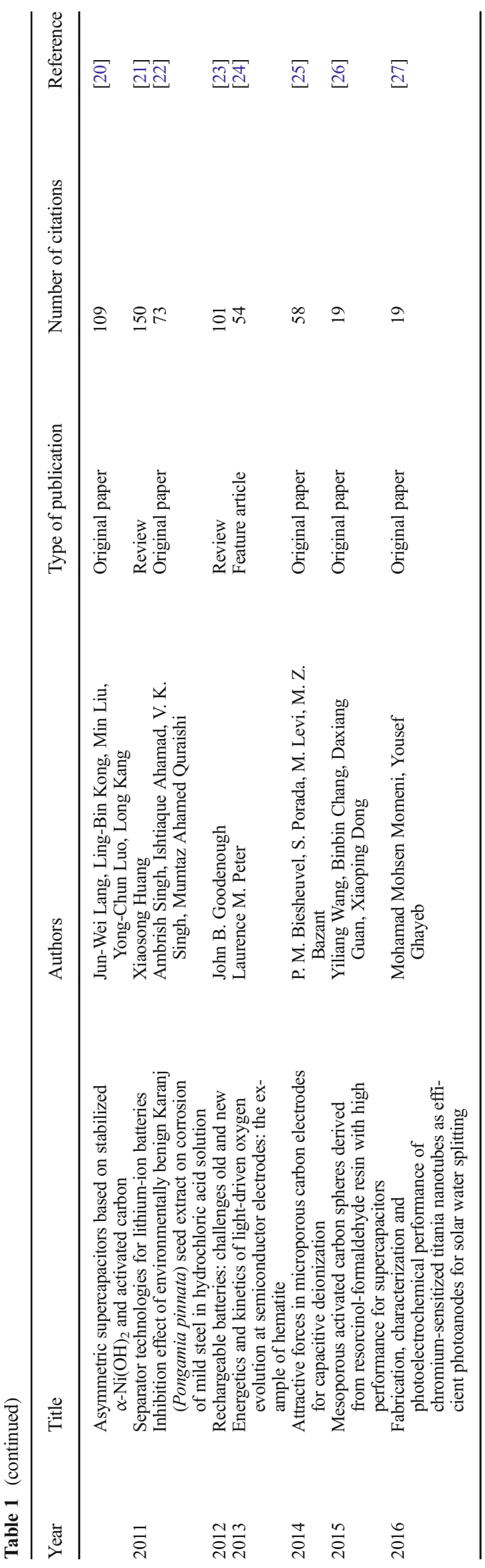

involved in the publishing process, which is nowadays a very diverse and globalized business, requiring constant attention and experienced stewardship.

A particular highlight of the last 20 years was the special issue "Electrochemistry-Past, Present and Future" (No. 7-8, 2011) published to celebrate the International Year of Chemistry in 2011. This issue is actually a book with 548 pages, containing reviews written by world experts. I am forever being congratulated on its publication and asked if it might be re-published in the form of a monograph. Although I understand this request, the online electronic access to the material ensures that everybody can download these reviews at any time.

Dr. Svetlana Zakharchenko has kindly analyzed the publications of the last 20 years with respect to the number of citations they have got. The results are given in Table 1, where the most frequently cited papers of each year in the years 1997 to 2016 are listed. If the most frequently cited paper is a review, the most frequently cited original paper is also given. Sincere thanks go to these authors, and of course to all other authors who cannot be listed here.

No journal can be published without an armada of dedicated reviewers: they perform the key step in the publication process. The quality control of the journal is in their hands. Without them, the scientific literature would rapidly decay. In this regard, let me mention here the work of J. O'M. Bockris as a reviewer: his reports were masterpieces with respect to science, ethics, and far-sightedness. He was very severe where science and accuracy were concerned; yet, he never tried to force authors to reference his own papers, and he never asked for the rewriting of passages which he would have written differently. I well remember his remark "I would not have written it this way, but if the authors like to write it that way, let them do so" (not verbatim). This tolerance of the "handwriting of the author" is certainly a noble quality of a reviewer.

Now let us try to look into the future: one does not have to be a prophet to predict that electromobility, electric power sources, and storage devices will continue to be hot topics of international research and development. In any case, this trend is obvious in recent Tables of Contents of the journal and will, no doubt, continue into the future. I am pleased to report that the journal has not shifted completely to applied research but still maintains a healthy balance of papers on theoretical topics. The reviews published in this anniversary issue by Doron Aurbach et al. [28], Hiroki Nara et al. [29], Diana Golodnitsky [30], Tobias Placke [31], Ivo Hümmelgen [32], and George Inzelt [33] clearly point to current trends. Regular readers of the journal will also be aware that we are publishing papers in the field of electroanalysis. Progress in electroanalysis and electrochemical sensors is currently certainly slower than progress in power sources and storage devices, but some spectacular developments are occurring: the development of dating procedures for metals (see the 
review of Antonio Domenèch-Carbó in this issue) provides an impressive example of the application of solid state electroanalysis. The field of conducting polymers, reviewed by George Inzelt in this issue, has high significance for almost all electrochemistry, batteries, fuel cells, supercapacitors, sensors, etc. It will remain a pillar of our publication scope. Theoretical electrochemistry (see e.g., steady-state electrolysis [34], voltammetry at three-phase junction [35], DOCC site concept [36], voltammetry at three-phase junction [5], corrosion current densities [37], non-Marcus model for electrostatic fluctuations in long-range electron transfer [38], electron transfer [39, 40], Tafel slopes [41], convolution [42], IL double layer [43], equivalent circuit for C-based supercapacitors [44], single molecule transistor [45], steady-state voltammetry [46], capillarity and electrocapillarity of solid interfaces [47], normally rather rare in all journals, is another topic which will continue to be cultivated in our journal. We will also continue to draw the attention of our readers to the history of electrochemistry, e.g., history of platinum single crystal electrochemistry [48], double layer effects in electrode kinetics [49], electrochemical phase formation [50], nonaqueous media in electrochemistry [51, 52], lithium batteries [53], free energy relationships [54], solid electrolyte fuel cells [55], glass electrode [56], electrochemical stripping techniques [57], electrode kinetics [58], osmotic theory [59], and theories of electrochemical double layer [60], ionic strength and electrode kinetics [61], Nernst equation [62], as we believe that this is a prerequisite for knowing where we have come from and where we have to go.

The future of the journal will depend on new and younger editors, who will certainly bring in fresh ideas and enthusiasm. Therefore, we are constantly appointing new members of the editorial board (Stephen Fletcher and José Zagal in 2011), and from time to time also new topical editors, when that is desirable (2009 Galina Tsirlina for theoretical electrochemistry, 2012 Antonio Doménech-Carbó for solid state electroanalysis and Palani Balaya for batteries, supercapacitors and fuel cells, 2016 Yair Ein-Eli for fuel cells, batteries and supercapacitors, and Henny Bouwmeester for solid state electrochemistry). In 2007, the decision was made to replace Regional Editors with Topical Editors, because this allowed a more focussed manuscript handling. This, too, has been a success.

Electrochemical technologies are essential for the future of mankind, and so the progress in electrochemical fundamentals and applied research will continue to be of interest. These same topics will also maintain a flourishing electrochemical literature, to which we will add our own share!

I have initiated the foundation of the journal and served as Editor-in-Chief from the first day onwards. As we enter the third decade of the journal, I look forward to the future with continued optimism.

\section{References}

1. Lovrić M, Scholz F (1997) J Solid State Electrochem 1:108-113

2. Golabi SM, Noor-Mohammadi F (1998) J Solid State Electrochem 2:30-37

3. Kharton VV, Yaremchenko AA, Naumovich EN (1999) J Solid State Electrochem 3:303-326

4. Shalini Rodrigues, N. Munichandraiah, A. K. Shukla (1999) J Solid State Electrochem 3:397-405

5. Schröder U, Oldham KB, Myland JC, Mahon PJ, Scholz F (2000) J Solid State Electrochem 4:314-324

6. Kleperis J, Wójcik G, Czerwinski A, Skowronski J, Kopczyk M, Beltowska-Brzezinska M (2001) J Solid State Electrochem 5:229249

7. Tallman DE, Spinks G, Dominis A, Wallace GG (2002) J Solid State Electrochem 6:73-84

8. Razmi-Nerbin H, Pournaghi-Azar M (2002) J Solid State Electrochem 6:126-133

9. Conway BE, Pell WG (2003) J Solid State Electrochem 7:637-644

10. Bramnik NN, Bramnik KG, Buhrmester Th, Baehtz C, Ehrenberg H, Fuess H (2004) J Solid State Electrochem 8:558-564

11. Davies TJ, Banks CE, Compton RG (2005) J Solid State Electrochem 9:797-808

12. Zhou H, Chen H, Luo Sh, Lu G, Wie W, Kuang Y (2005) J Solid State Electrochem 9:574-580

13. Christensen J, Newman J (2006) J Solid State Electrochem 10:293319

14. Xu M-W, Bao Sh-J, Li H-L (2007) J Solid State Electrochem 11: 372-377

15. Tsipis EV, Kharton VV (2008) J Solid State Electrochem 12:13671391

16. Holloway AF, Wildgoose GG, Compton RG, Shao L, Green MLH (2008) J Solid State Electrochem 12:1337-1348

17. Lindner E, Gyurcsányi RE (2009) J Solid State Electrochem 13:5168

18. Lang J-W, Kong L-B, Wu W-J, Liu M, Luo Y-Ch, Kang L (2009) J Solid State Electrochem 13:333-340

19. Chunwen Sun, Rob Hui, Justin Roller (2010) J Solid State Electrochem 14:1125-1144

20. Lang J-W, Kong L-B, Liu M, Luo Y-Ch, Kang L (2010) J Solid State Electrochem 14:1533-1539

21. Huang X (2011) J Solid State Electrochem 15:649-662

22. Singh A, Ahamad I, Singh VK, Quraishi MA (2011) J Solid State Electrochem 15:1087-1097

23. Goodenough JB (2012) J Solid State Electrochem 16:2019-2029

24. Peter LM (2013) J Solid State Electrochem 17: 315-326

25. Biesheuvel PM, Porada S, Levi M, Bazant MZ (2014) J Solid State Electrochem 18: 1365-1376

26. Wang Y, Chang B, Guan D, Dong X (2015) J Solid State Electrochem 19: 1783-1791

27. Momeni MM, Ghayeb Y (2016) J Solid State Electrochem 20:683 689

28. Sharon D, Hirshberg D, Afri M, Frimer AA, Noked M, Aurbach D (2017) J Solid State Electrochem this issue

29. Nara H, Tsuda Sh, Osaka T (2017) J Solid State Electrochem this issue

30. Strauss E, Menkin S, Golodnitsky D (2017) J Solid State Electrochem this issue

31. Placke T, Kloepsch R, Dühnen S, Winter M (2017) J Solid State Electrochem this issue

32. Hümmelgen IA (2017) J Solid State Electrochem this issue

33. Inzelt G (2017) J Solid State Electrochem this issue

34. Oldham KB (1997) J Solid State Electrochem 1:36-44

35. Oldham KB (1998) J Solid State Electrochem 2:367-377

36. Maser K (1999) J Solid State Electrochem 4:3-16 
37. Alfred RL, Myland JC, Oldham KB (2002) J Solid State Electrochem 6:172-182

38. Fletcher S (2007) J Solid State Electrochem 11:965-969

39. Fletcher S (2008) J Solid State Electrochem 12:765-770

40. Fletcher S (2010) J Solid State Electrochem 14:705-739

41. Fletcher S (2009) J Solid State Electrochem 13:537-549

42. Mahon PJ (2009) J Solid State Electrochem 13:573-582

43. Kornyshev AA, Luque NB, Schmickler W (2014) J Solid State Electrochem 18:1345-1349

44. Fletcher S, Black VJ, Kirkpatrick I (2014) J Solid State Electrochem 18:1377-1387

45. Fletcher S (2015) J Solid State Electrochem 19:241-250

46. Oldham KB, Marken F, Myland JC (2016) J Solid State Electrochem 20:3083-3095

47. Gutman EM (2016) J Solid State Electrochem 20:2929-2950

48. Climent V, Feliu JM (2011) J Solid State Electrochem 15:12971315
49. Fawcett WR (2011) J Solid State Electrochem 15:1347-1358

50. Milchev A (2011) J Solid State Electrochem 15:1401-1415

51. Izutsu K (2011) J Solid State Electrochem 15:1719-1731

52. Gritzner G (2011) J Solid State Electrochem 15:1791-1797

53. Scrosati B (2011) J Solid State Electrochem 15:1623-1630

54. Appleby AJ, Zagal JH (2011) J Solid State Electrochem 15:18111832

55. Möbius H-H (1997) J Solid State Electrochem 1:2-16

56. Scholz F (2011) J Solid State Electrochem 15:5-14

57. Scholz F (2011) J Solid State Electrochem 15:1509-1521

58. Inzelt G (2011) J Solid State Electrochem 15:1373-1389

59. Inzelt G (2006) J Solid State Electrochem 10:1008-1011

60. Damaskin BB, Petrii OA (2011) J Solid State Electrochem 15: 1317-1334

61. Tsirlina GA (2017) J Solid State Electrochem this issue

62. Scholz F: J Solid State Electrochem this issue 